\title{
Design and Research of Smart Neck Helmets Based on the KANO-QFD Model and TRIZ Theory
}

\author{
Deng Zhao and Weiwei Chen \\ School of Industrial Design, Hubei University of Technology, Wuhan, Hubei 430000, China \\ Correspondence should be addressed to Weiwei Chen; 201810932@hbut.edu.cn
}

Received 13 July 2021; Revised 7 September 2021; Accepted 14 September 2021; Published 7 October 2021

Academic Editor: Joni Zhong

Copyright (c) 2021 Deng Zhao and Weiwei Chen. This is an open access article distributed under the Creative Commons Attribution License, which permits unrestricted use, distribution, and reproduction in any medium, provided the original work is properly cited.

In order to better serve the safety protection of urban residents during cycling, the KANO model is used to analyze the problems encountered by users wearing helmets during cycling. Combined with QFD, the weighted average analysis of user needs and the importance of engineering measures of product technical characteristics is carried out and users are found. We used TRIZ innovative invention principles to analyze the key requirements and converted them into TRIZ standard problems. We used the corresponding invention measures to improve the existing problems of the helmet and verified the rationality of the design through finite element analysis. Through the KANO-QFD model combined with the TRIZ innovative invention principle, the helmet is optimized to improve its safety.

\section{Introduction}

With the rapid development of cycling tools and the increase of vehicle speeds, the currently available protective helmets on the market are gradually showing insufficient safety in terms of safety. The accident rate of motorcycles/battery bikes continues to rise. In the event of a collision, due to inertia and other reasons, the center of mass of the helmet will shift and the torque of the neck joint will increase. This increases the risk of the driver's neck injury. The human neck is composed of cervical muscles, vertebrae, ligaments, and so on. Its structure is small and its bearing capacity is weak. [1] The neck is not only the passage for blood vessels, trachea, esophagus, and spinal cord, but also the movement of the head relative to the trunk. In the high acceleration (high $\mathrm{G}$ ) riding environment, neck injuries are most likely to occur. Cervical spine injury cannot be manifested immediately, and fracture or dislocation is not the most serious injury of cervical spine. Among them, the absence of nerve damage and its extent, as well as the possibility of nerve damage in the future, are potentially serious injuries.

TRIZ theory is a systematic and innovative theory for solving contradictory problems established by a team led by the former Soviet Union G. SAltshuller through researching 2.5 million high-level patents around the world. Solve problems more rationally for design practitioners. At present, TRIZ theory has been combined with other research methods to form a complementary integrated theory. For example, $\mathrm{Hu}$ et al. [2] combined AD and TRIZ theory and applied them to the product design of protective helmets. This effectively solves the independence of the helmet function. Zhang et al. [3] used three theoretical integration models of E, HOQ, and TRIZ to make up for the limitations of the single design theory and combined the advantages of the three theories for innovative design. Aiming at the shortcomings of the inability to determine the design problem in the TRIZ theory, Zhang et al. [4] combined quality function deployment (QFD) to determine a variety of design problems through QFD analysis and used the innovative solution of TRIZ theory [5] to improve the product design process and improve the efficiency of product development. Xie [6] combined the house of quality (HOQ), the core tool of QFD, with TRIZ to assist in product fuzzy front-end stage demand decision-making, technical feature decision-making, and technical conflict decision-making research and providing support. Zhang et al. [7] combined 
FA and TRIZ theory to establish the relationship between function and structure components. A component interaction matrix was formed, and the structure and function design of the anterior maxillary traction appliance was optimized. And finite element analysis (FEA) was used to conduct comparative experiments on the improved design and evaluate and analyze the plan.

Therefore, when the helmet products used by cyclists are impacted, the helmet not only protects the neck, but also causes the problem of neck damage. By using the combination of KANO and QFD to discover technical contradictions in helmet products, it provides quantitative basis and design innovation points for the innovative design of helmets. Find the principle of invention through the contradiction matrix in TRIZ theory. Use the principle of invention to solve the contradiction and get the innovative design scheme of the smart neck helmet. Then, use the finite element analysis software ANSYS to evaluate and analyze the product plan and finally obtain a design plan based on the KANO/QFD/TRIZ integrated method. This effectively improves the safety performance of the helmet and provides the most powerful guarantee for traffic safety.

The user needs are transformed through the KANO model and introduced into the judgment matrix of product characteristics in QFD to provide a quantitative basis and design innovation points for the design of the helmet. Discover the contradictions in technical requirements through the contradiction matrix in TRIZ theory. Use the principle of invention to solve the contradiction and get the innovative design scheme of the smart neck helmet. Then use the finite element analysis ANSYS software to evaluate and analyze the product plan, and finally obtain a design plan based on the KANO/QFD/ TRIZ integrated method. This effectively improves the safety performance of the helmet and provides the most powerful guarantee for traffic safety.

\section{KANO/QFD/TRIZ Integration Method}

In order to improve and improve the defects of existing products, the combination of KANO and QFD models is required. Parameterize the user demand data obtained through questionnaire surveys, and quantify the design requirements. Complementary with the advantages of TRIZ tools, find the corresponding invention principles through TRIZ theory, and finally solve technical problems and obtain product innovation.

The theoretical research process is divided into the following four steps:

Step 1: use the KANO model to conduct a questionnaire survey. According to the data obtained from the survey, it is calculated separately by the percentage formula of the functional attribute classification. $\mathrm{Ob}$ serve the ratio of exciting needs $(A)$, functional needs $(O)$, basic needs $(M)$, and indifferent needs $(I)$ among users to the $i$-th user needs, respectively, denoted as $A_{i}$, $O_{i}, M_{i}$, and $I_{i}$.
The specific value is calculated by the formula of SI and DSI:

$$
\begin{aligned}
\mathrm{SI}_{i} & =\left(\frac{A_{i}+O_{i}}{A_{i}+O_{i}+M_{i}+I_{i}}\right), \\
\mathrm{DSI}_{i} & =-1\left(\frac{A_{i}+O_{i}}{A_{i}+O_{i}+M_{i}+I}\right) .
\end{aligned}
$$

Step 2: according to the importance of engineering technical measures obtained by weight, the characteristics of technical requirements are obtained, and the conflict type is determined through negative correlation analysis. Suppose the weight of the $i$-th user demand is $w_{i}$ :

$$
\begin{aligned}
& \omega_{i}=\max \left(\frac{\mathrm{SI}_{i}}{\sum_{i=1}^{m} \mathrm{SI}_{i}}, \frac{\left|\mathrm{DSI}_{i}\right|}{\sum_{i=1}^{m}\left|\mathrm{DSI}_{i}\right|}\right), \\
& h_{j}=\sum_{i=1}^{m} \omega_{i} r_{i j} .
\end{aligned}
$$

In formula (3), $w_{i}$ is the importance of the $i$-th quality requirement after correction.

$R_{i j}$ is the digital value corresponding to the symbol of the relationship between the $i$-th quality requirement and the j-th technical characteristic [8].

$\mathrm{j}=1,2, \ldots, n$ is the number of product characteristics; $i=1,2, \ldots, m$ is the number of user requirements.

After the degree of importance is converted, user needs are transformed into engineering characteristics, and the degree of importance of engineering characteristics is obtained.

Step 3: enter the obtained key technical performance importance and user requirements into HOQ. According to the traditional HOQ method, the key technical performance and importance ranking of motorcycle helmets are analyzed, and according to the established autocorrelation matrix of the technical characteristics of the HOQ roof, it is judged that there is a negative correlation between the technical characteristics.

Step 4: use TRIZ theory to resolve conflicts. Identify and analyze the negative correlation technical features in HOQ. Transform key design issues into TRIZ standard issues. Through the contradiction matrix in TRIZ theory, the conflicts can be summarized as technical contradictions or physical contradictions. The technical contradiction is solved by finding the corresponding 40 invention principles with the help of the contradiction matrix. Physical contradiction uses the principle of separation to find the specific invention principle corresponding to this type of contradiction. Combining user needs and the importance of key technical performance, determine the final application of the invention principle. Finally, a product design scheme based on the $\mathrm{KANO} / \mathrm{QFD} / \mathrm{TRIZ}$ integration method is obtained (as shown in Figure 1). 


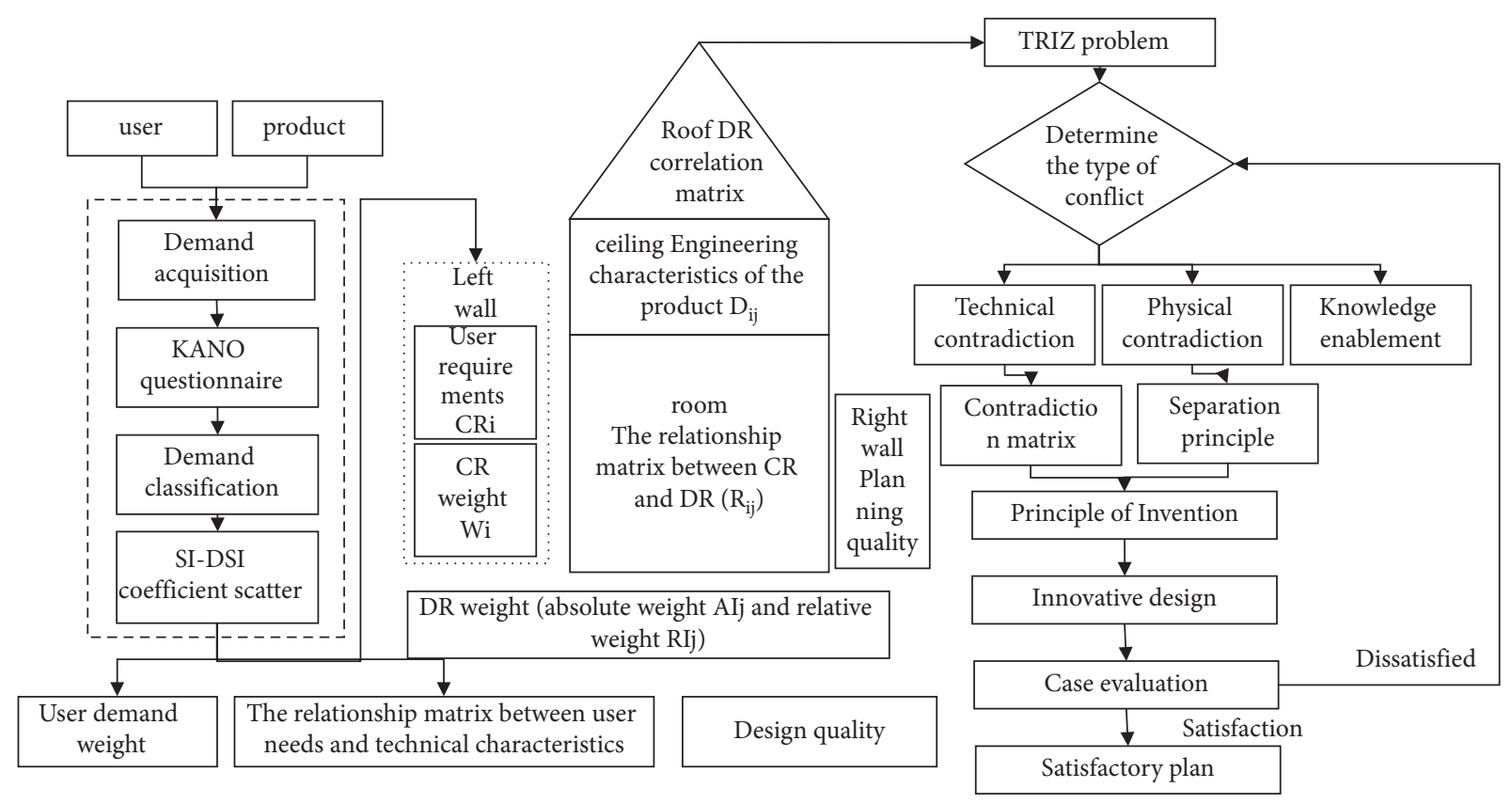

FIgURE 1: KANO-QFD, TRIZ innovative design process.

\section{Conceptual Innovative Design of Smart Neck Helmets Based on KANO/QFD/TRIZ Theory}

3.1. Obtaining Specific Description of User Needs. Through interviews and dialogues with users, the most real needs of users can be collected. Since the information content answered by the user will appear in many forms, after the interview is over, it is necessary to organize and summarize the user's answers and convert the relevant content raised by the user's interview into quality requirements. Table 1 is a sample record of the results of user interviews.

Use the KJ method to organize the user needs hierarchically, so that the indicators can be quantitatively evaluated. The user needs are divided into safety performance (A-type indicators), comfort performance (Btype indicators), aesthetic performance (C-type indicators), and functional performance (D-type indicators). Perform subdivision of secondary demand indicators under various performances. The analysis of user needs hierarchy is shown in Table 2 .

\subsection{KANO Questionnaire Analysis and Demand Ranking.} The KANO questionnaire design was carried out on the above-mentioned user demand index content, and 598 copies were collected, and the collected questionnaires were classified and evaluated. Statistics of the changing trend of various demands under the first-level demand indicators mainly observe the change trend of basic requirements $(\mathrm{M})$, functional requirements $(\mathrm{O})$, and excitement requirements (A). SI represents user satisfaction when a product has a certain function. DSI represents user dissatisfaction when a product does not have a certain function. The calculated sensitivity coefficient model after sorting is shown in Table 3.
In Table 4, the SI coefficient represents the satisfaction coefficient after adding this function, and the DSI represents the dissatisfaction coefficient after eliminating this function. By solving the weight of each user demand, sorting among the four demand types, the maximum value is obtained. Among the functional requirements, the three most weighted items are automatically cleaning rainwater in rainy days, intelligently identifying obstacles, and improving impact resistance. Among the basic needs, the first three items are more convenient, lighter, and tough. In the exciting demand, combine with airbags, have neck protection function, and look for materials with high comfort. Every requirement of the basic type must be met. The first three items of the functional type can satisfy the user experience, and the excitement type can improve the user experience in combination with user needs. At present, most of the helmets on the market still have potential safety hazards for users in terms of safety performance. The higher demand of users is increased, and the user experience can be greatly improved.

In Table 5, according to the calculated importance of various engineering and technical measures, the product characteristics are ranked. The first six items are sorted by hj.: Neck protection design $>$ Operation settings $>$ Sensor application $>$ Smart recognition of obstacles $>$ Effectively improve the anticollision strength $>$ Multifunction integration. Among them, the item whose relationship degree $R_{i j}$ is 9 under each product characteristic and user demand is as follows: Neck guard design corresponds to A1 (with neck guard function), A2 (combined with airbag). The sensor application corresponds to A2 (combined with airbag), and the effective recognition of obstacles corresponds to A3 (intelligent recognition of obstacles). Multifunction integration corresponds to D1 (Bluetooth, turn signal, and other multifunction integration), D4 (voice navigation). The 
TABle 1: Sample form of user interview record.

\begin{tabular}{|c|c|}
\hline Personal information & $\begin{array}{l}\text { Occupation: } 3 \text { food delivery staff, } 3 \text { employees, } 3 \text { cycling enthusiasts; age: } \\
\text { 22-32 }\end{array}$ \\
\hline Behaviour when you want to turn during a ride & $\begin{array}{l}\text { Unable to observe from the rearview mirror, you need to turn your head left } \\
\text { and right to observe the situation of the car behind } \\
\text { Slow down when turning, and the car behind does not know }\end{array}$ \\
\hline Safety requirements for helmet products & $\begin{array}{l}\text { It protects the head well, protects the face well, and protects the neck well } \\
\text { I hope I can answer the phone without taking off my helmet, I hope I do not }\end{array}$ \\
\hline Performance requirements for helmet products & $\begin{array}{l}\text { have to take out my mobile phone for navigation, turn signal prompts, and } \\
\text { road condition reminders }\end{array}$ \\
\hline Functional expectations for helmet products & $\begin{array}{l}\text { I hope I can answer the phone without taking off the helmet, I hope the road } \\
\text { conditions are reminded, I hope I can interact with the helmet intelligently, } \\
\text { and remind dangerous situations }\end{array}$ \\
\hline Is there any inconvenience during use? & $\begin{array}{l}\text { Use half helmet, can not cover splashes. The ventilation performance of the full } \\
\text { helmet is too poor and the quality is heavier, with a little oppressive feeling. } \\
\text { Hairstyle is messed up every time, I always feel that the safety performance is } \\
\text { not enough }\end{array}$ \\
\hline $\begin{array}{l}\text { If there is a helmet with perfect } \\
\text { complete functions, would you }\end{array}$ & $\begin{array}{l}\text { To meet the multi-functional needs, the product safety performance is also } \\
\text { satisfied, the operation method is simple, I will consider buying } \\
\text { If the price is not very expensive, I would like to try the product }\end{array}$ \\
\hline
\end{tabular}

TABle 2: Primary screening of user needs.

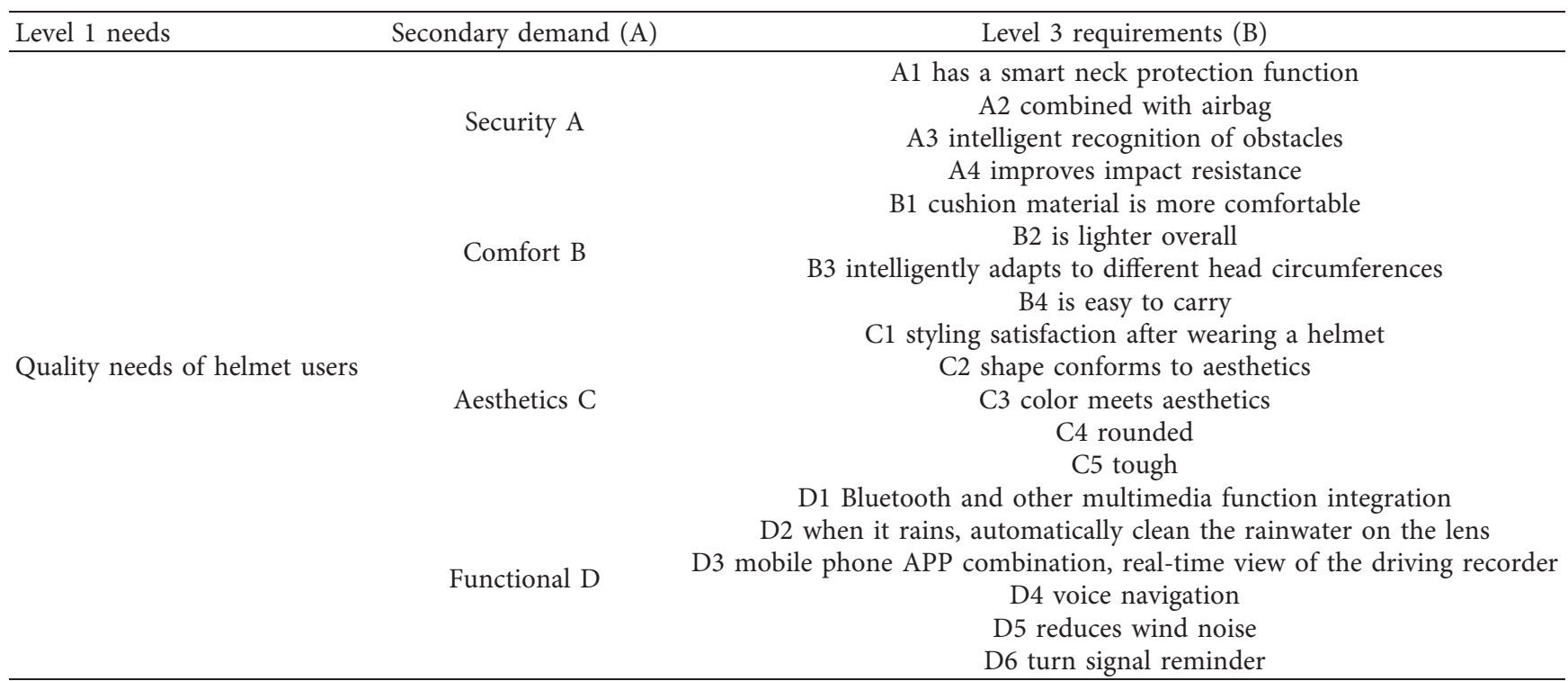

operation setting corresponds to A2 (combined with airbag). The degree of noise reduction corresponds to D5 (reducing wind noise when riding). The helmet body material corresponds to A4 (improved impact resistance). Human-computer interaction and rescue tools correspond to D3 (combined with mobile phone APP, real-time view of driving recorder).

\section{Innovative Design of TRIZ Theory}

4.1. Description of Helmet Use Problems. According to the user weight obtained by the above KANO questionnaire and the importance of engineering measures $\mathrm{Hj}$ of HOQ in the QFD method, the contradiction problem is determined by combining product characteristics, and the contradiction is resolved by using the principle of invention and creation in TRIZ theory.
In TRIZ theory, the fundamental core of solving practical problems in invention is to resolve conflicts. To use TRIZ theory, we must first determine technical conflicts. Use 39 general engineering parameters in TRIZ theory and technology conflict to describe its design conflict, find the contradiction matrix, select the most suitable innovation method in the innovation principle, and carry out the design content, as shown in Table 6.

4.2. TRIZ Principle Solution. Effectively solve the technical contradiction in the helmet through the principle of invention:

Contradiction 1: the protection area in the safety protection performance is not perfect, and the protection at the neck is basically absent. 
TABLE 3: Various demand sensitivity factors.

\begin{tabular}{|c|c|c|c|c|c|c|c|c|c|}
\hline $\begin{array}{l}\text { Level } 1 \\
\text { heading }\end{array}$ & Secondary heading & Numbering & $\begin{array}{c}\mathrm{A} \\
\text { (charming } \\
\text { type) }\end{array}$ & $\begin{array}{c}\mathrm{O} \\
\text { (expected) }\end{array}$ & $\begin{array}{c}\mathrm{M} \\
\text { (required } \\
\text { type) }\end{array}$ & $\begin{array}{c}\text { I (no } \\
\text { difference) }\end{array}$ & SI & |DSI $\mid$ & KANO attributes \\
\hline \multirow{4}{*}{ Safety } & $\begin{array}{l}\text { With smart neck } \\
\text { protection function }\end{array}$ & A1 & 102 & 212 & 193 & 91 & 0.525 & 0.677 & $\begin{array}{c}\text { Necessary } \\
\text { requirements }\end{array}$ \\
\hline & Incorporate airbag & A2 & 162 & 196 & 172 & 68 & 0.599 & 0.615 & Expected demand \\
\hline & $\begin{array}{l}\text { Intelligent recognition } \\
\text { of obstacles }\end{array}$ & A3 & 157 & 215 & 187 & 41 & 0.622 & 0.672 & Expected demand \\
\hline & $\begin{array}{l}\text { Improve impact } \\
\text { resistance }\end{array}$ & $\mathrm{A} 4$ & 155 & 214 & 142 & 87 & 0.617 & 0.595 & Expected demand \\
\hline \multirow{4}{*}{ Comfort } & $\begin{array}{l}\text { The cushion material is } \\
\text { more comfortable }\end{array}$ & B1 & 143 & 150 & 178 & 126 & 0.490 & 0.548 & Basic needs \\
\hline & $\begin{array}{c}\text { The overall mass is } \\
\text { lighter }\end{array}$ & B2 & 162 & 98 & 225 & 113 & 0.435 & 0.540 & Basic needs \\
\hline & $\begin{array}{l}\text { Intelligently adapt to } \\
\text { different head } \\
\text { circumferences }\end{array}$ & B3 & 158 & 140 & 192 & 108 & 0.498 & 0.555 & $\begin{array}{l}\text { Essential } \\
\text { foundation }\end{array}$ \\
\hline & Easy to carry & B4 & 94 & 177 & 195 & 132 & 0.453 & 0.622 & $\begin{array}{c}\text { Necessary } \\
\text { requirements }\end{array}$ \\
\hline \multirow{5}{*}{ Aesthetics } & $\begin{array}{l}\text { Modeling satisfaction } \\
\text { after wearing a helmet }\end{array}$ & $\mathrm{C} 1$ & 101 & 232 & 75 & 190 & 0.557 & 0.513 & Expected demand \\
\hline & $\begin{array}{c}\text { The shape meets the } \\
\text { aesthetics }\end{array}$ & $\mathrm{C} 2$ & 136 & 147 & 154 & 161 & 0.473 & 0.503 & $\begin{array}{c}\text { Undifferentiated } \\
\text { demand }\end{array}$ \\
\hline & The color is aesthetic & $\mathrm{C} 3$ & 132 & 157 & 143 & 166 & 0.483 & 0.502 & $\begin{array}{c}\text { Undifferentiated } \\
\text { demand }\end{array}$ \\
\hline & Mellow & $\mathrm{C} 4$ & 133 & 161 & 190 & 114 & 0.492 & 0.587 & $\begin{array}{l}\text { Necessary } \\
\text { requirements }\end{array}$ \\
\hline & Tough & C5 & 113 & 156 & 210 & 119 & 0.450 & 0.612 & $\begin{array}{l}\text { Necessary } \\
\text { requirements }\end{array}$ \\
\hline \multirow{5}{*}{ Feature } & $\begin{array}{c}\text { Multifunctional } \\
\text { integration of } \\
\text { Bluetooth, turn signal, } \\
\text { etc. }\end{array}$ & D1 & 97 & 229 & 166 & 106 & 0.545 & 0.66 & Expected demand \\
\hline & $\begin{array}{l}\text { In rainy days, } \\
\text { automatically clean the } \\
\text { rainwater on the lens }\end{array}$ & D2 & 113 & 192 & 207 & 86 & 0.510 & 0.667 & $\begin{array}{l}\text { Necessary } \\
\text { requirements }\end{array}$ \\
\hline & $\begin{array}{l}\text { Combination of mobile } \\
\text { phone APP, real-time } \\
\text { view of driving recorder }\end{array}$ & D3 & 166 & 169 & 231 & 32 & 0.560 & 0.669 & $\begin{array}{l}\text { Necessary } \\
\text { requirements }\end{array}$ \\
\hline & Voice navigation & D4 & 115 & 187 & 221 & 75 & 0.505 & 0.648 & $\begin{array}{l}\text { Necessary } \\
\text { requirements }\end{array}$ \\
\hline & Reduce wind noise & D5 & 166 & 185 & 192 & 55 & 0.587 & 0.630 & $\begin{array}{l}\text { Necessary } \\
\text { requirements }\end{array}$ \\
\hline
\end{tabular}

Preoperation according to NO.10 (specially arrange the object in advance to make it ready in time or already in a position that is easy to operate). The sensor is used to monitor the external impact force. In the event of a traffic accident, the sensor will transmit the monitored impact force to the microprocessor, and the microprocessor will send a signal to the neck protector according to the instructions. Through the use of innovative theory NO.29 pneumatic and hydraulic structure (inflatable mattress), the form of the neck protector is designed into an airbag deployment type. When the compressed gas in the airbag receives pressure, it starts to do work. Wrap the neck in a transitional form (as shown in Figure 2).
Paradox 2: the additional devices (neck protectors, communications, infrared sensors, etc.) installed on the helmet significantly increase the weight of the helmet. According to the innovative principle NO.1 segmentation (increasing the degree of independent parts between objects), each function is designed to be segmented on the helmet body, such as the design of the turn signal, which is set on the back side of the helmet body.

Paradox 3: the lens cannot be cleaned and refreshed in real time on rainy days, blocking the line of sight. Use the innovative principle NO.1 to improve the design of the lens device. A smaller cleaning device will be arranged between the helmet body and the buffer layer. Move the lens device from the outside of the helmet 
TABLE 4: User demand weight sorting table.

\begin{tabular}{lccc}
\hline Numbering & Secondary heading & Weights & Demand type \\
\hline A3 & Intelligent recognition of obstacles & 0.0662 & Functional requirements \\
A4 & Improve impact resistance & 0.0656 & Functional requirements \\
A2 & Combined with airbags & 0.0637 & Functional requirements \\
A1 & With neck protection function & 0.0626 & Functional requirements \\
D5 & Reduce wind noise & 0.0624 & Functional requirements \\
D3 & Combine with the mobile APP to view the driving recorder in real time & 0.0619 & Functional requirements \\
D2 & In rainy days, automatically clean the rainwater on the lens & 0.0617 & Functional requirements \\
D1 & Multifunctional integration of Bluetooth, turn signal, etc. & 0.0610 & Functional requirements \\
D4 & Voice navigation & 0.0599 & Basic needs \\
C1 & Modeling satisfaction after wearing a helmet & 0.0592 & Basic needs \\
B4 & Easy to carry & 0.0575 & Basic needs \\
C5 & Tough & 0.0566 & Basic needs \\
C4 & Mellow & 0.0543 & Basic needs \\
B3 & Intelligently adapt to different head circumferences & 0.0530 & Basic needs \\
B1 & The cushion material is more comfortable & 0.0521 & Exciting demand \\
C3 & Sense of science and technology & 0.0514 & Exciting demand \\
C2 & Simple atmosphere & 0.0503 & Exciting demand \\
B2 & Light in mass & 0.0499 & Exciting demand \\
\hline
\end{tabular}

body to the inside of the helmet body. The combined design of the cleaning device and the lens allows the lens to be automatically cleaned every time it is stowed.

Contradiction 4: to adapt to the head circumference, use the principle of segmentation to split out a part on the left and right sides of the helmet body to design the knob. The knob operation corresponds to the adjustment of the head circumference. Wear the helmet and rotate it to adjust the head circumference to ensure that the user can adjust the helmet before driving. Contradiction five: functions such as communication and voice navigation while driving are difficult to use. According to NO.2 (separate the key part of the object), separate the operating device from the helmet. The user's interactive function of the helmet is transferred to the operating device through the operating device. The operating device is installed on the handle of the car closest to the hand, facilitating the user's interactive operation. That is, when turning a corner, touch the interactive operation device, and the turn signal of the smart helmet will light up accordingly. And voice navigation, driving recorder, and other functions can reduce the user's direct interactive operation of the helmet through the interactive operation device, making the driving process more safe and avoiding the hand from leaving the handlebar.

Contradiction 5: functions such as communication and voice navigation while driving are difficult to use. According to the NO.24 intermediary principle (interactive operations of communication and other functions cannot be performed on the helmet; the intermediary is required to realize the interactive work of the helmet), the interactive operation device is individually designed to be concrete. The user's interactive function of the helmet is transferred to the operating device through the operating device. The operating device is installed on the handle of the car closest to the hand, facilitating the user's interactive operation. That is, when turning a corner, touch the interactive operation device, and the turn signal of the smart helmet will light up accordingly. Voice navigation, driving recorder, and other functions can all reduce the user's direct interactive operation of the helmet through the interactive operation device, making the driving process more safe and avoiding the hand from leaving the handle of the car.

4.3. Introduction to the Innovative Design of the Smart Neck Helmet. According to the conflict resolution of the TRIZ principle and the HOQ analysis result in the QFD method, the innovative concept scheme of the smart neck helmet is obtained by combining the product characteristics, as shown in Figures 3-8.

The overall smart neck protector is divided into 3 parts: helmet, neck protector, and operating device. The innovative design of the timely neck protection airbag is integrated into the smart helmet, and the airbag is released as soon as a traffic accident occurs, and the neck is firmly wrapped to ensure the safety of the driver's life. The operating device will be placed on both sides of the car handle, and the driver does not need to leave the car handle to interact with the helmet, making the smart helmet more secure in terms of safety.

\section{Helmet Airbag Design by Finite Element Analysis Simulation Theory}

5.1. Simulation Theory. Through the TRIZ innovation theory, the technical contradictions in the design process were resolved, and a new innovative design was proposed. The helmet has a harder shell, and the shell of different materials will have different effects on the force. Therefore, this time only the simulation analysis of the neck protector in the new design scheme is carried out, and the feasibility of the neck 


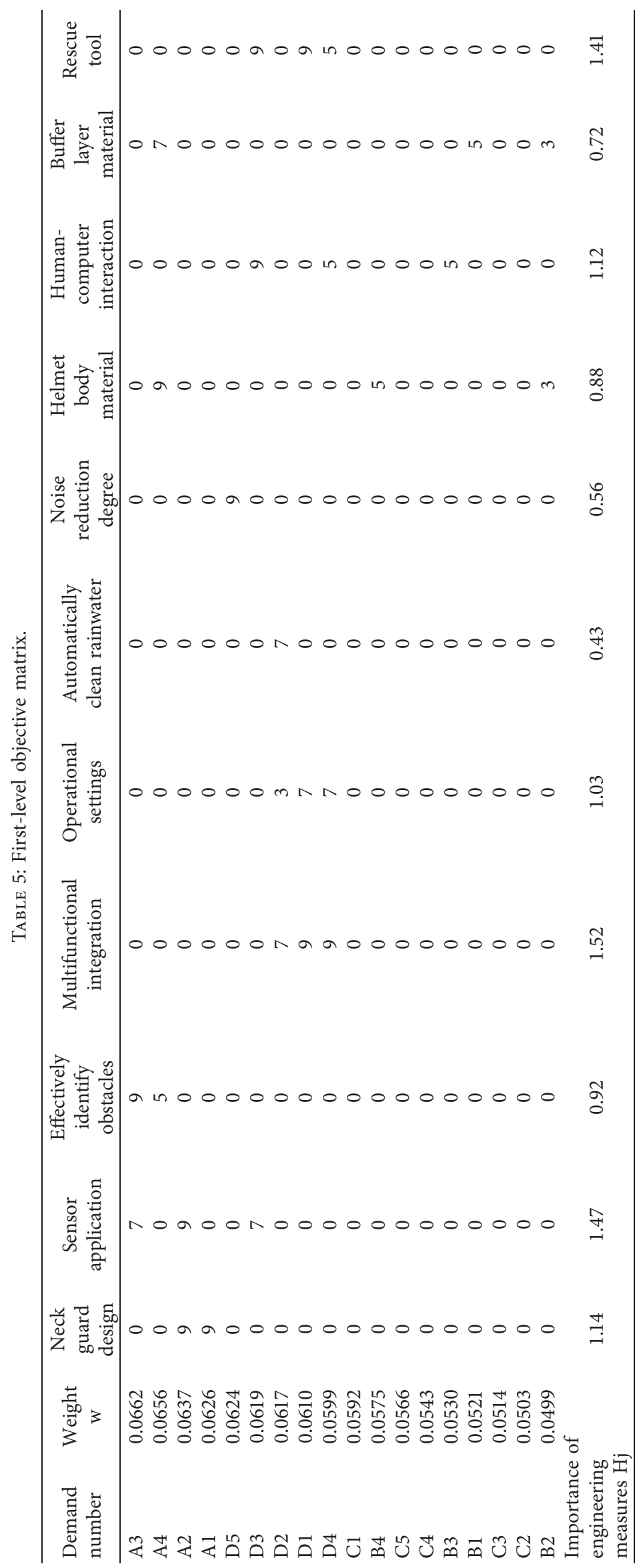


TABLE 6: Standard issues and innovative methods.

\begin{tabular}{|c|c|c|c|c|}
\hline Usage problem & $\begin{array}{l}\text { Convert to TRIZ } \\
\text { standard question }\end{array}$ & $\begin{array}{l}\text { TRIZ innovation } \\
\text { theory and } \\
\text { method } \\
\end{array}$ & Method of choice & Corresponding practical operation \\
\hline $\begin{array}{l}\text { 1. The safety protection is not in } \\
\text { place and the neck is easily } \\
\text { injured }\end{array}$ & $\begin{array}{l}\text { 11. Stress or pressure } \\
\text { 2. Mass of a } \\
\text { stationary object }\end{array}$ & $13,29,10,18$ & $\begin{array}{l}\text { 10. Preoperation } \\
\text { 29. Pneumatic and } \\
\text { hydraulic structure }\end{array}$ & $\begin{array}{c}\text { The protection of the neck is done by } \\
\text { airbags. }\end{array}$ \\
\hline $\begin{array}{l}\text { 2. The helmet body is slightly } \\
\text { heavier }\end{array}$ & $\begin{array}{l}\text { 2. Mass of stationary } \\
\text { objects } \\
\text { 39. Productivity }\end{array}$ & $1,28,15,35$ & 1. Divide & $\begin{array}{l}\text { Each functional module is designed } \\
\text { through the principle of division. }\end{array}$ \\
\hline $\begin{array}{l}\text { 3. The lens cannot be cleaned } \\
\text { and refreshed in real time when } \\
\text { it rains, blocking the sight }\end{array}$ & $\begin{array}{l}\text { 38. Degree of } \\
\text { automation } \\
\text { 32. Manufacturability }\end{array}$ & $8,28,1$ & 1. Divide & $\begin{array}{c}\text { The lens device is moved to the inner side } \\
\text { of the helmet body, and a cleanable } \\
\text { cleaning device is set at the same time. } \\
\text { Every time the lens is stowed, it will be } \\
\text { cleaned. }\end{array}$ \\
\hline \multicolumn{5}{|l|}{$\begin{array}{l}\text { 4. Adapt to the head } \\
\text { circumference }\end{array}$} \\
\hline $\begin{array}{l}\text { 5. Communication and other } \\
\text { functions are difficult to use } \\
\text { while driving }\end{array}$ & $\begin{array}{l}\text { 33. Operability } \\
\text { 36. Complexity of the } \\
\text { device }\end{array}$ & $27,9,26,24$ & $\begin{array}{l}\text { 24. Intermediary } \\
\text { principle }\end{array}$ & $\begin{array}{l}\text { Because the interactive operation device } \\
\text { with communication and other functions } \\
\text { is not suitable for being placed on the } \\
\text { helmet, the interactive operation device } \\
\text { is designed separately and placed near } \\
\text { the handlebar according to the } \\
\text { intermediary principle. }\end{array}$ \\
\hline
\end{tabular}

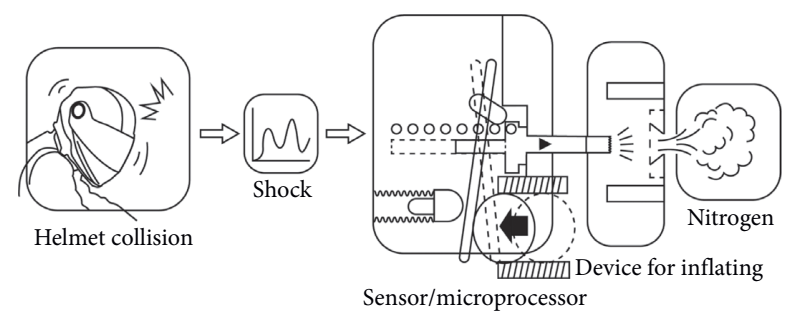

FIgURE 2: Working principle diagram of the helmet airbag.

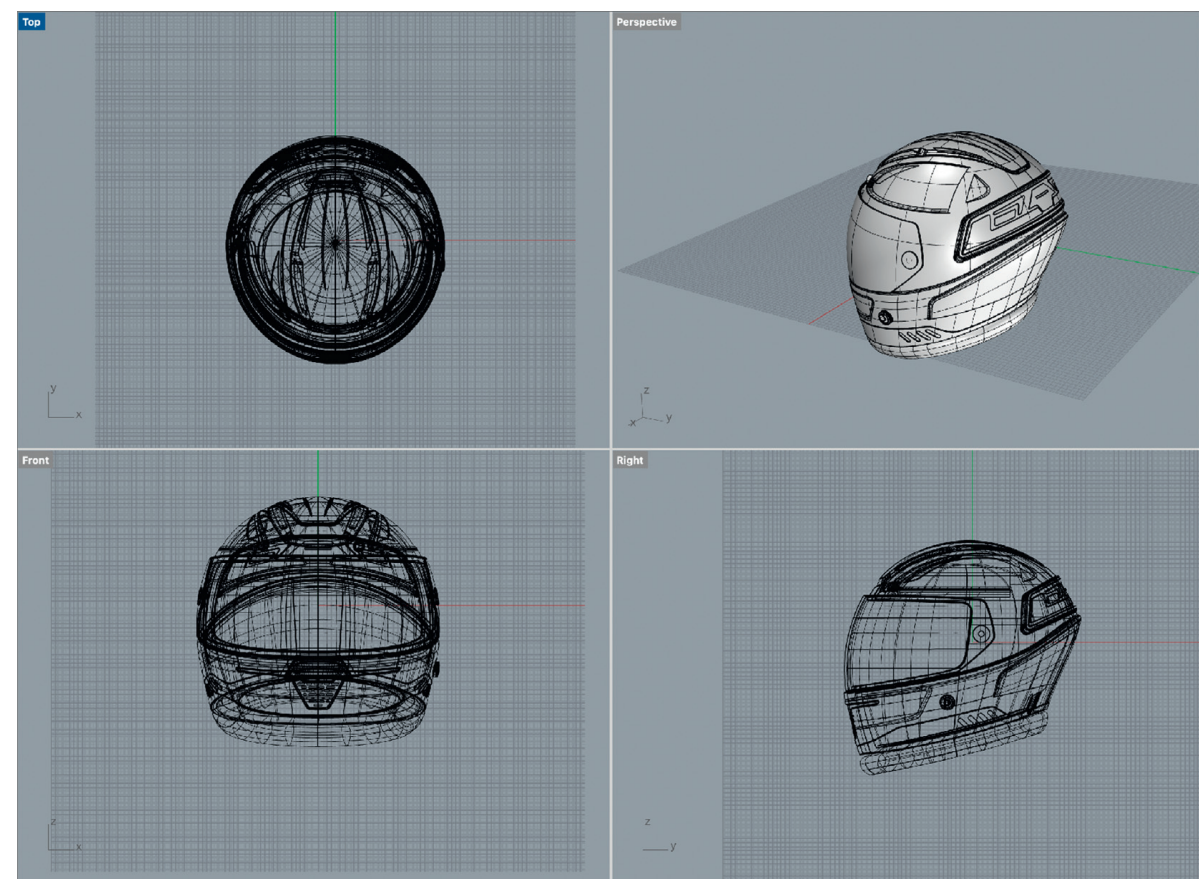

FIgure 3: Three-dimensional modeling display. 


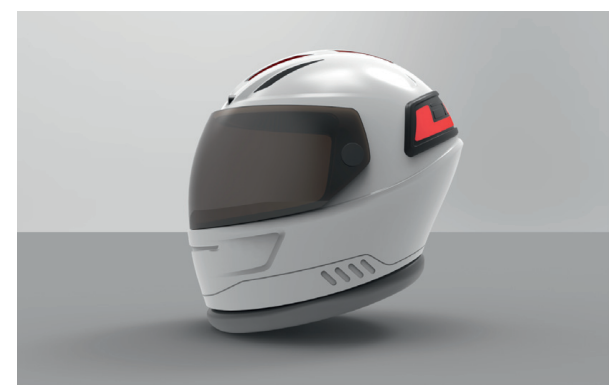

FIgURE 4: Smart neck helmet.

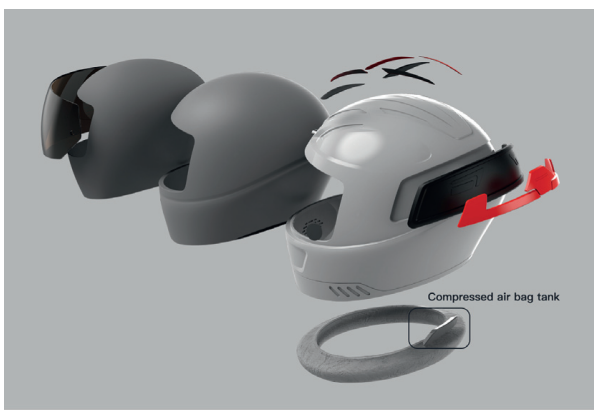

Figure 5: Airbag compression tank.

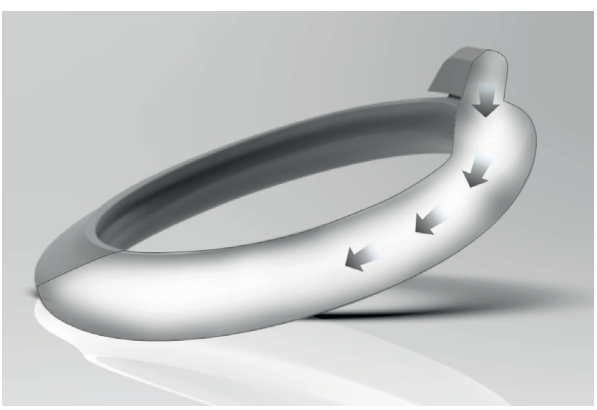

Figure 6: Airbag-compressed air tank gas-flow state display.

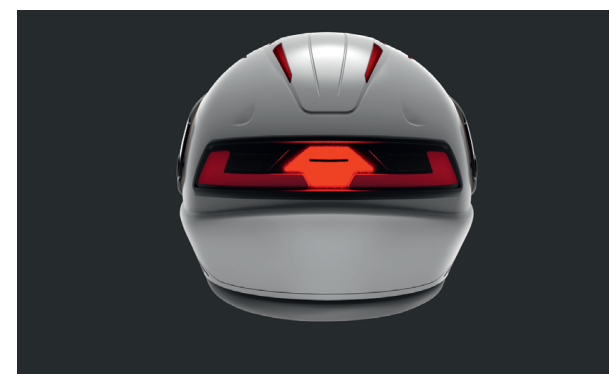

FIgURE 7: Turn signal function display.

protector is verified through the force and energy absorption.

The ANSYS Workbench Explicit Dynamics display dynamics module is used. Explicit dynamics uses explicit algorithms to solve dynamic equations, effectively avoiding the convergence problems in invisible algorithms. The dynamic explicit algorithm uses the difference format of the dynamic equation, and the calculation speed is fast, and it is

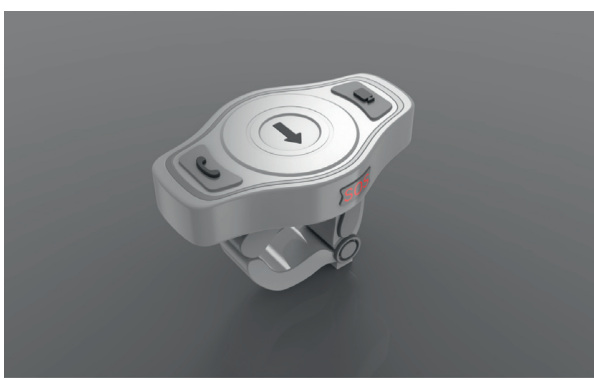

FIGURE 8: Display of effect diagram of the wireless remote control operation device.

not necessary to solve the tangent stiffness and balance iteration. Therefore, the memory required is less than the implicit algorithm. The numerical calculation is relatively simple, but the explicit algorithm requires the quality matrix to be a diagonal matrix, and the speed advantage can only be exerted when the unit-level calculation is as small as possible. The reduced integration method is usually used to activate the hourglass mode, which affects the calculation accuracy of stress and strain. Effectively simulate large deformations and nonlinear solutions of materials. follows:

The basic governing equations of dynamics are as

$$
[M]\left\{U_{2}\right\}+[C]\left\{U_{0}\right\}+[K]\{U\}=\{F(t)\} .
$$

Here, $[M]$ is the structural quality matrix. $[C]$ is the structural damping matrix. $[K]$ is the structural stiffness matrix. $\{F\}$ is the load function that changes over time. $\{U\}$ is the nodal displacement vector. $\left\{U_{1}\right\}$ is the node velocity vector. $\left\{U_{2}\right\}$ is the node velocity vector.

5.2. Test Material Properties. In Table 7, Nylon 66 is synthesized through adipic acid and hexamethylene diamine, and its characteristics are high strength, high toughness, and wear resistance. The melting point is as high as 265 degrees Celsius, and the performance can be maintained at a high temperature of 150 degrees Celsius. The airbag needs to be inflated with high-pressure gas instantly, and the selected material should have high-pressure resistance and good airtightness and stretchability in order to fully absorb the impact energy in a collision accident without breaking the damage.

Nylon airbags use tetrahedron as the main division unit in ANSYS workbench mesh, as shown in Table 8.

5.3. Simulation Analysis. Simulate the force of the airbag during a driver collision. When the collision occurs, the airbag expands, and the human body and the airbag collide with the obstacle. The collision speed is $70 \mathrm{~km} / \mathrm{h}$, and the collision time is $0.0001 \mathrm{~s}$. The collision simulation is shown in Figures 9-12.

It can be seen from Figure 13 that the collision process at high speed is very short, only 0.0001 seconds. When nylon is used as the airbag material, the stress increases to $46 \mathrm{Mpa}$ at the beginning of the collision. The contact continues after 
TABLE 7: Nylon material properties.

\begin{tabular}{lc}
\hline Material properties & Material property parameters \\
\hline Density & $1150 \mathrm{~kg} / \mathrm{m}^{3}$ \\
Elastic modulus & $0.0283 e 5 \mathrm{MPa}$ \\
Poisson's ratio & 0.4 \\
Tensile strength & $75.46 \mathrm{MPa}$ \\
Elongation at break & $50 \%$ \\
Yield strength & $54.88 \mathrm{MPa}$ \\
Compressive strength & $103.88 \mathrm{MPa}$ \\
Flexural modulus & $2.89 \mathrm{GPa}$ \\
Impact strength & $1.20 \mathrm{~kJ} / \mathrm{M} / \mathrm{M}$ \\
\hline
\end{tabular}

TABLE 8: Unit properties.

\begin{tabular}{lc}
\hline Cell size & $1 \mathrm{~mm}$ \\
\hline Number of units & 10092 \\
Orthogonal quality & 0.89748 \\
Slope & 0.24256 \\
Unit quality & 0.92565
\end{tabular}

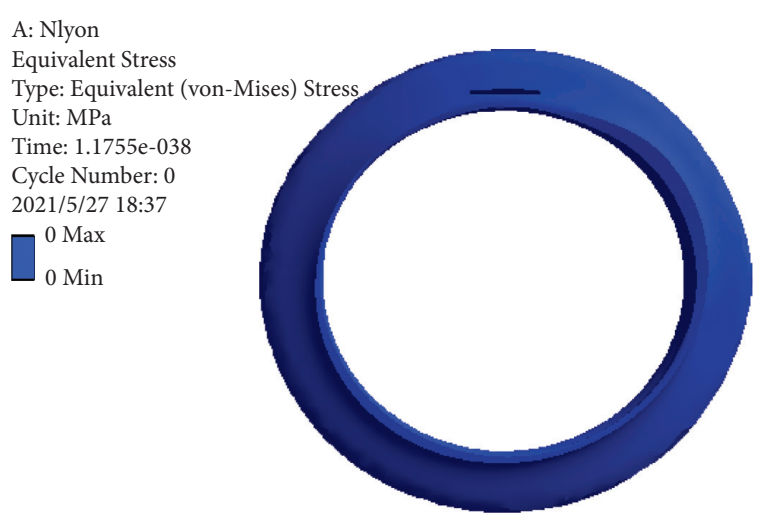

FIgURE 9: Simulation at $1.1755 e-38 \mathrm{~s}$ at first contact.

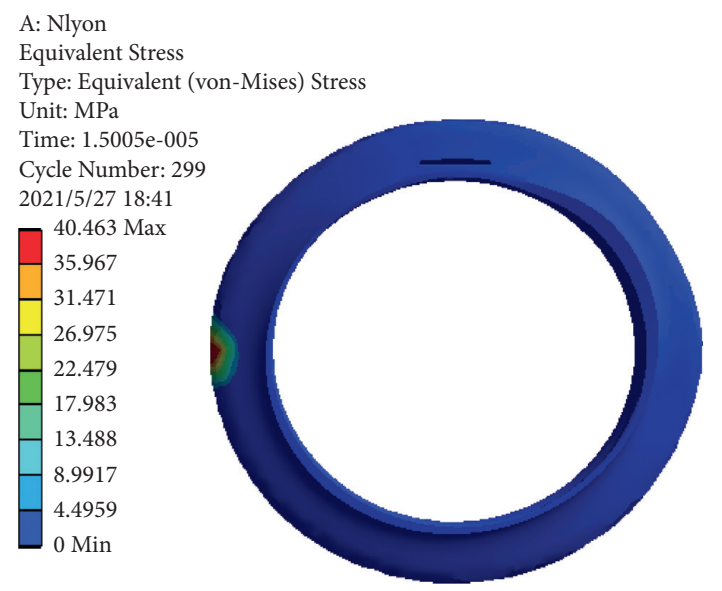

FIGURE 10: Simulation when contacting at $5.036 e-5 \mathrm{~s}$.

the inertial collision, but the final stress increase is very small to $49 \mathrm{MPa}$, and the stress change curve is gentle, which can effectively reduce the driver's injury when the vehicle occurs in a collision accident and avoid a secondary collision of the

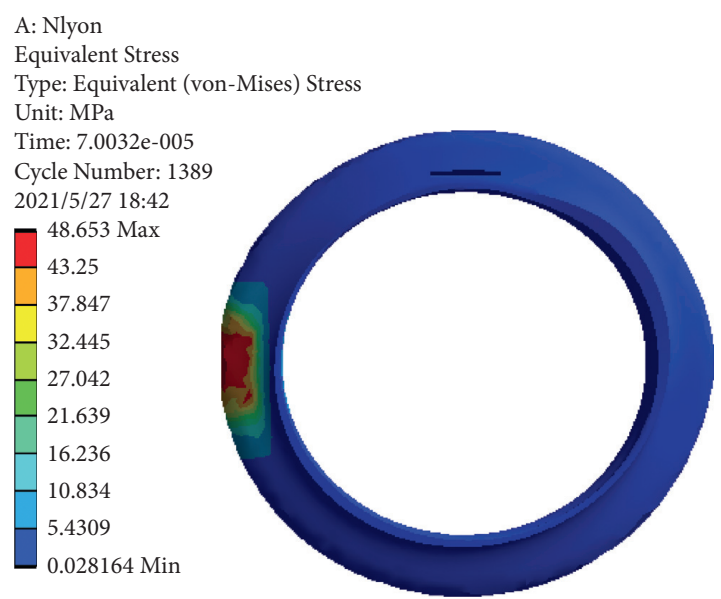

FIGURE 11: Simulation when contacting at $1.0005 e-5 \mathrm{~s}$.
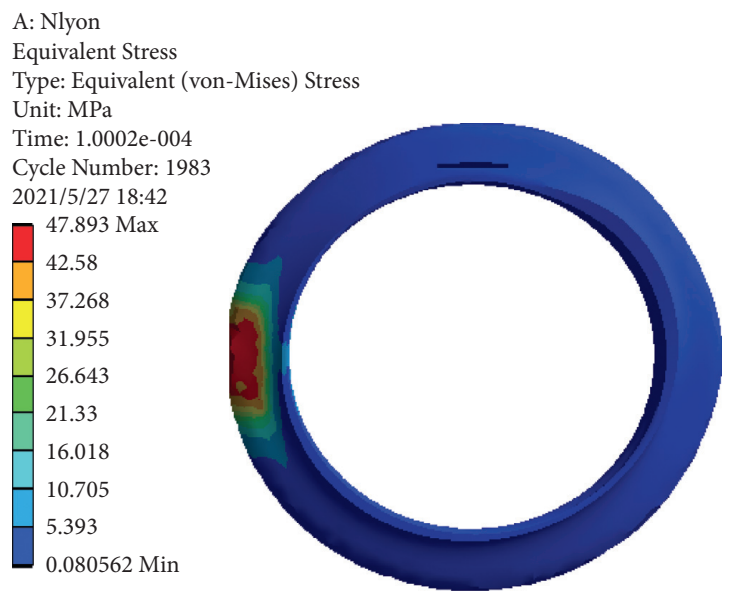

Figure 12: Simulation when contacting at $1 e-4 \mathrm{~s}$.

driver's neck. This shows that the nylon protective airbag has a good cushioning effect during the collision and can effectively protect the driver's neck.

It can be seen from Figure 14 that the deformation of the protective airbag is close to linear change during the collision after the collision begins. Using nylon for airbag protection, although the deformation continues to increase, the force change is gentle and basically remains unchanged. With buffering, the force is very small and the stress does not increase with the increase of deformation. When a car is hit by a violent impact from the front, the driver will rush forward due to inertia. When the head hits the airbag that pops up instantly, the airbag will be compressed and displaced greatly to protect the head.

When the protective part is replaced with a harder object, the collision simulation and stress changes are shown in Figures 15-18 when the nylon protective airbag protection is removed.

From Figures 19 and 20, it can be seen that, after removing the nylon protective airbag, the stress increases significantly with the increase of contact time after an impact at a speed of $70 \mathrm{~km} / \mathrm{h}$. After a side impact, the stress rises quickly, reaching several gigapascals quickly, which is very harmful to the human body. As the protection is removed, 


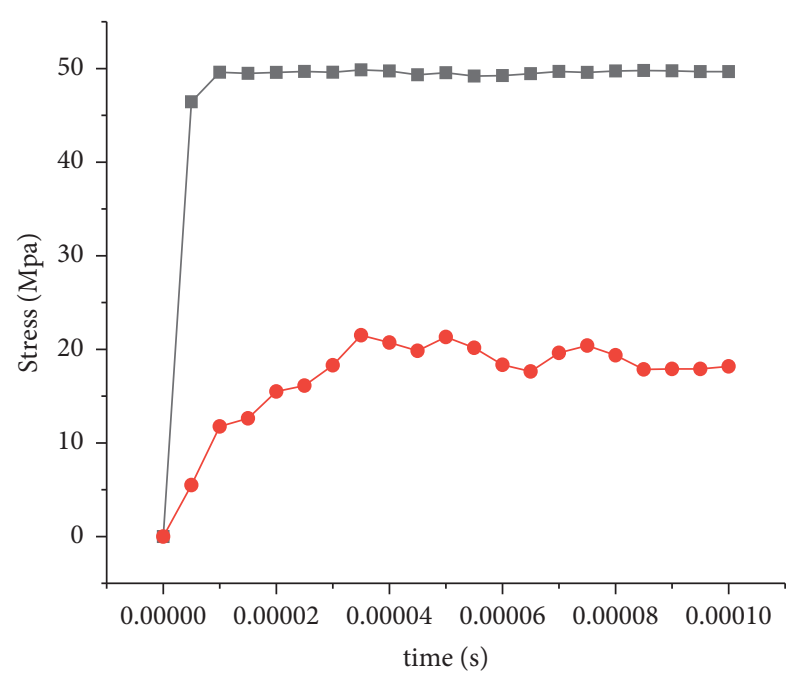

$\rightarrow-$ Maximum stress

$\longrightarrow$ Mean stress

Figure 13: Collision time and stress curve.

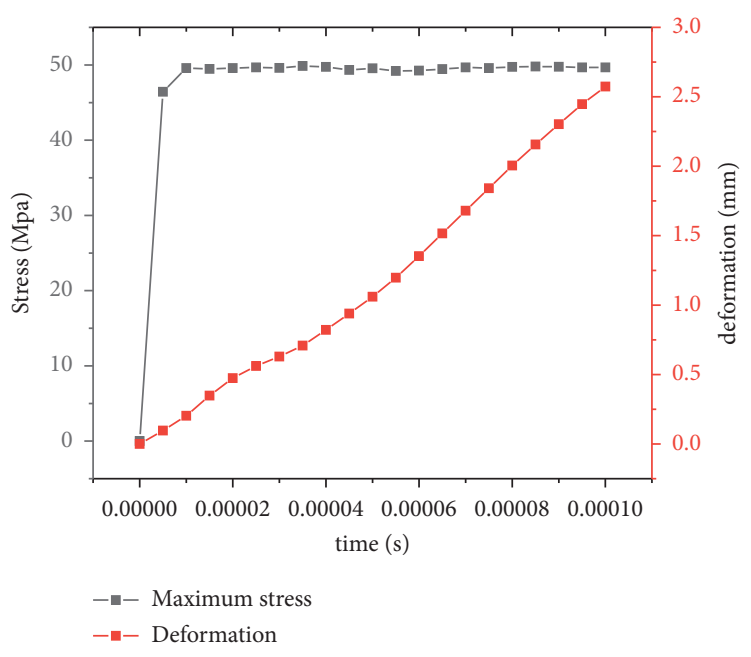

FIGURE 14: Stress and deformation curves.

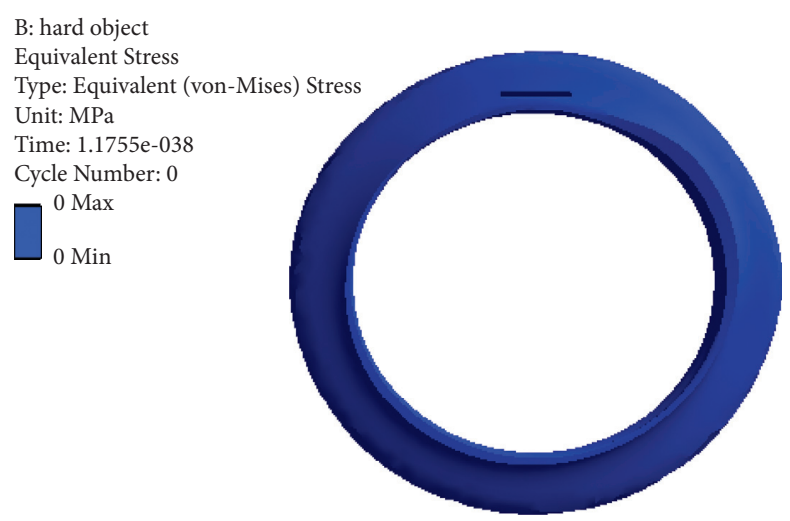

FIGURE 15: Stress at first contact.

the $2 \mathrm{~mm}$ displacement change cannot buffer the strong impact force at all, and the collision force cannot be buffered to cause serious harm to the driver.
According to the above data, it can be seen that the protective airbag designed with nylon as a material can well cushion the impact of a collision, and the contact stress 


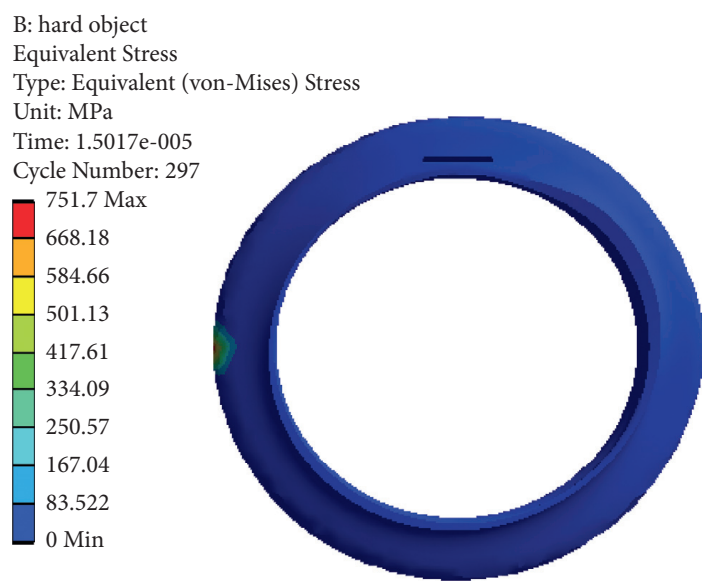

FIgURE 16: Stress when contacting at $5.083 e-6 \mathrm{~s}$.
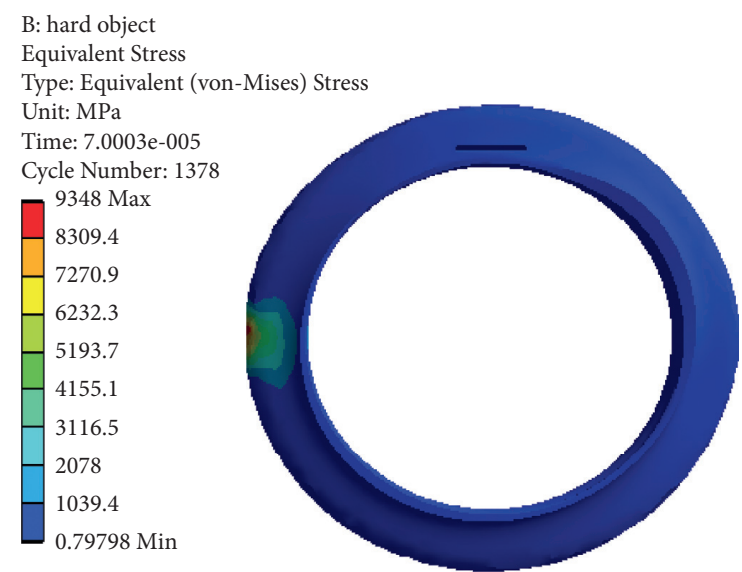

FIGURE 17: Stress when contacting at $5.083 e-6 \mathrm{~s}$.
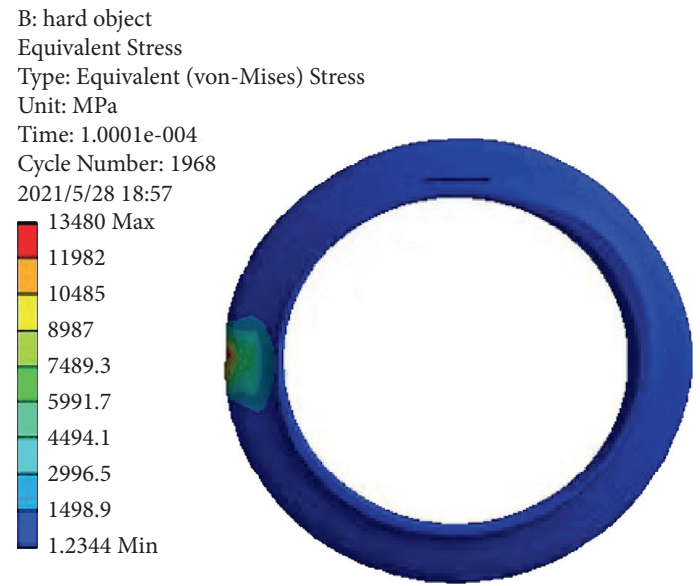

FIGURE 18: Stress when contacting at $1 e-4 \mathrm{~s}$.

changes smoothly after the collision and does not increase with the increase of the collision time. Due to the strength and elongation of the nylon fiber combined with the safety protection airbag designed this time, it can very effectively reduce the driver's injury.

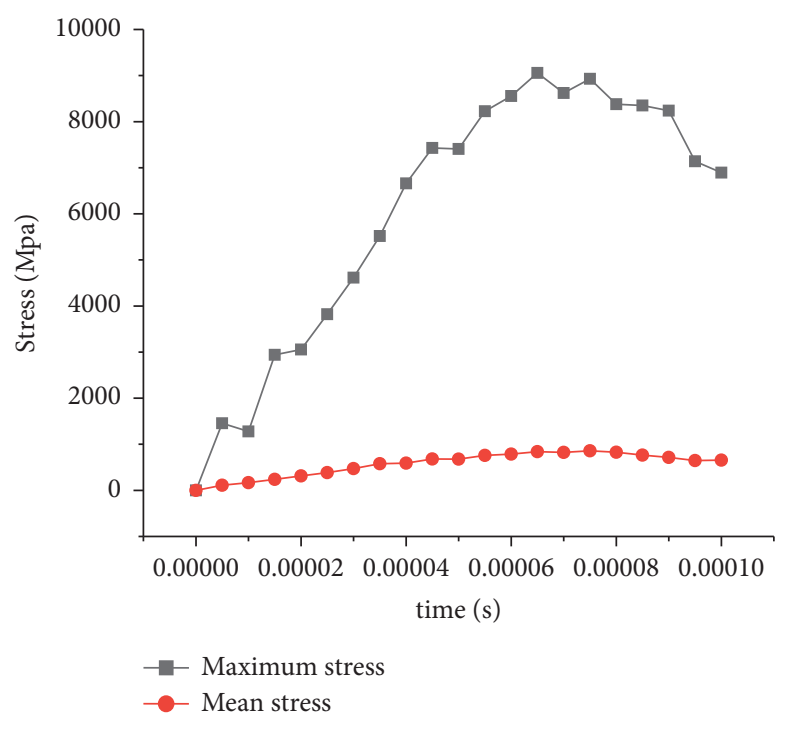

Figure 19: Contact stress change curve.

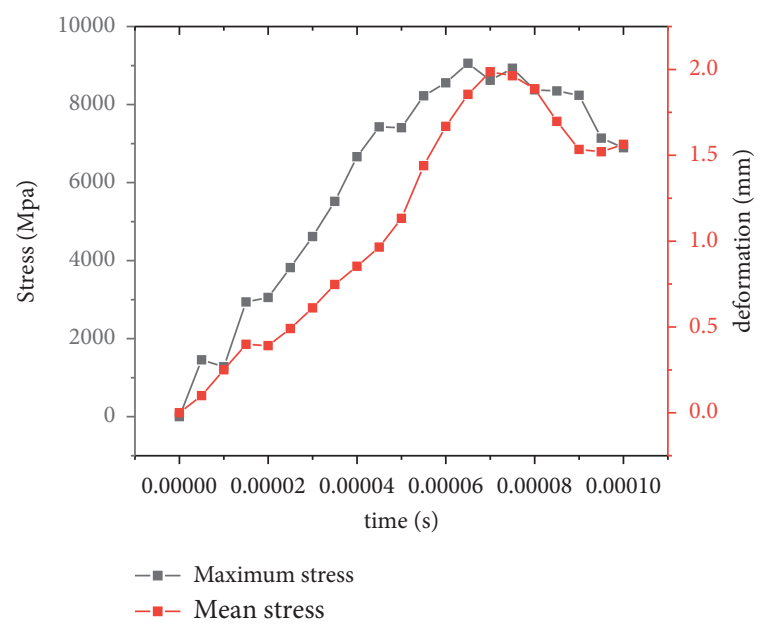

Figure 20: Contact stress and deformation curve.

\section{Summary}

(1) This article will take the design process of industrial design as the main body of research, use the KANO model to obtain accurate functional requirements, and transform them into design problems through QFD, how to quickly apply the TRIZ theory to the product plan innovation design process. Integrating TRIZ theory with KANO model and QFD theory in the design of helmet products can guide the process of product design, improve the optimal design of products, and provide a certain theoretical reference for designers' design products.

(2) Analyze and design according to the real needs of users to ensure that the functional requirements expected by users are met, improve the safety performance and functionality of the helmet, greatly protect the life safety of riders, and improve convenient services for riders. 
(3) Provide a new direction for helmet safety protection. It is no longer limited to head protection but also proposes neck protection to make the safety level more complete and proposes intelligent functional design to facilitate user riding and guide. It is of great significance for users to ride safely, which will reduce the injuries of traffic participants in accidents.

\section{Data Availability}

No data were used to support this study.

\section{Conflicts of Interest}

The authors declare that there are no conflicts of interest regarding the publication of this article.

\section{References}

[1] X. H. Jia, J. B. Mao, and R. C. Wang, "Acute neck injury of pilots under high G load," Chinese rehabilitation medicine association rehabilitation medicine engineering professional committee, Chinese disabled rehabilitation association rehabilitation engineering professional committee, tsinghua university precision instruments and mechanics department. Proceedings of the 7th national rehabilitation medicine engineering and rehabilitation engineering symposium, Tsinghua University Department of Precision Instruments and $\mathrm{Me}$ chanics: Chinese Association of Rehabilitation Medicine, Beijing, China, 2010.

[2] K. Hu, F. T. Xu, and X. f Ai, "Innovative design method of fire helmet integrated AD and TRIZ," Machine Design, vol. 34, no. 12, pp. 111-115, 2017.

[3] F. Zhang, H. J. Shi, and G. Q. Chen, "Research on the innovation method of man-machine product based on E/HOQ/ TRIZ," Journal of Graphics, vol. 37, no. 6, pp. 759-764, 2016.

[4] C. Zhang, F. Yang, and G. C. Ren, "Research on the integration mode of TRIZ and QFD in product innovation design method," Machine Design and Research, vol. 30, no. 5, pp. 30-33+37, 2014.

[5] Y. W. Shi and X. C. Zheng, "Research on the application of GQFD-TRIZ integration method in the design of police UAV," Journal of Graphics, vol. 40, no. 2, pp. 296-302, 2019.

[6] J. M. Xie, Research on Fuzzy Front-End Design of Product Innovation Based on HOQ and TRIZ, University of Electronic Science and Technology of China, Chengdu, China, 2013.

[7] F. L. Zhang, W. T. Yao, and L. J. Liu, "Study on the design method of anterior traction appliance for malocclusion based on FA/TRIZ," Journal of Graphics, vol. 41, no. 3, pp. 438-445, 2020.

[8] S. F. Yang, X. L. Fu, and W. J. Zhang, "The application of QFDbased house of quality technology in the design of universal reducer," Coal Mine Machinery, vol. 39, no. 6, pp. 148-150, 2018. 